\title{
Interconnection of the Degree of Risk and Life Cycle of the "Green Construction" Investment Projects
}

\author{
Natalia Lepehova ${ }^{1, *}$ and Vitaly Shoshinov ${ }^{2}$ \\ ${ }^{1}$ Capital Finance and humanitarian Academy, 90/17, Shosseinaya Street, Moscow, 109383, Russia \\ ${ }^{2}$ Moscow State University of Civil Engineering, 26, Yaroslavskoye shosse, Moscow, 129337, Russia
}

\begin{abstract}
This article analyses interconnection of the degree of risk and the life cycle of the "green building" investment projects, which is structured according to the life cycle. Main stages of the implementation of investment and construction project were considered, interconnection of the project life cycle and the level of project risk were presented in the form of graphical model, proposed a mathematical model of the risk calculation at different stages of the project life cycle, which is a function of depending on the different risk parameters.
\end{abstract}

\section{Introduction}

Organization formulates requirements imposed to the developed investment project depending on a concrete type of actual investment. Investment project is the most important document for such forms of investment as "green building", i.e. for forms of investment, which require large financial investments and financed at the expense of proper and borrowing costs. This project includes a complete list of sections and indexes, in addition, purpose of implementation of the investment project, its main parameters, amount of the necessary financial resources, indexes of its efficiency and its implementation schedule are reviewed obligatorily [1].

\section{Methods}

Assignment of the project to the particular classification group allows to determine the amount of pre-investment studies, to assess the risk degree of concludes, to formulate arranging goals of dozens of reviewed projects, to approach the task of the projects effectiveness assessment more specifically. Concept of the project life cycle is the time between appearance of the project and time of its liquidation. In this investigation its proposed to introduce the economic life cycle of the project concept, which is the duration of possession of the real estate object [2]. Usually this period is equal to $10-15$, the object "changes" its owner and its certainly much less than the physical life cycle, and in other words durability, which can reach 100 years.

*Corresponding author: nais999@yandex.ru 
Table 1. Structure of interconnections of the life cycle stages and general risk classification [3].

\begin{tabular}{|l|l|l|}
\hline Phase & Stages & Risk profile \\
\hline $\begin{array}{l}\text { Preinvestm } \\
\text { ent }\end{array}$ & 1. Predesign works & $\begin{array}{l}\text { Is characterized by the highest level of risk because of } \\
\text { the temporal remoteness from realization of the final } \\
\text { production and the associated uncertainties (business, } \\
\text { political, financial, economic, etc.) }\end{array}$ \\
\hline Investment & $\begin{array}{l}\text { Is characterized by the high level of risk, as this step is } \\
\text { the most input intensities and, consequently, is } \\
\text { accompanied by the risk of the biggest losses in the } \\
\text { continuing uncertain situation }\end{array}$ \\
\hline $\begin{array}{l}\text { Exploitatio } \\
\mathrm{n}\end{array}$ & $\begin{array}{l}\text { 1. Pre-commissioning } \\
\text { activities } \\
\text { 2. Commissioning } \\
\text { 3. Project Closure }\end{array}$ & $\begin{array}{l}\text { Characterized by the lowest level of risk. Risk of } \\
\text { fluctuations in product demand and changes in the } \\
\text { competitive environment is the main }\end{array}$ \\
\hline
\end{tabular}

Division not on the stages, but on the steps of the investment intensity is more interesting for investment building project (ISP) effectiveness assessment (fig. 1) [4]. Investment building project should be divided onto three steps: pre-investment, investment and exploitation inasmuch as these steps have different level of risk (Table. 1). It's supposed that the beginning of the calculated period of investment building project the degree of the risk of the project failure is maximum and decreases with approach to the end of the life cycle of the project. It is caused by the gradual refinement of the cash flows, the reduction of the uncertainty risk in the external environment and transformation of investment project in the real estate object [5].

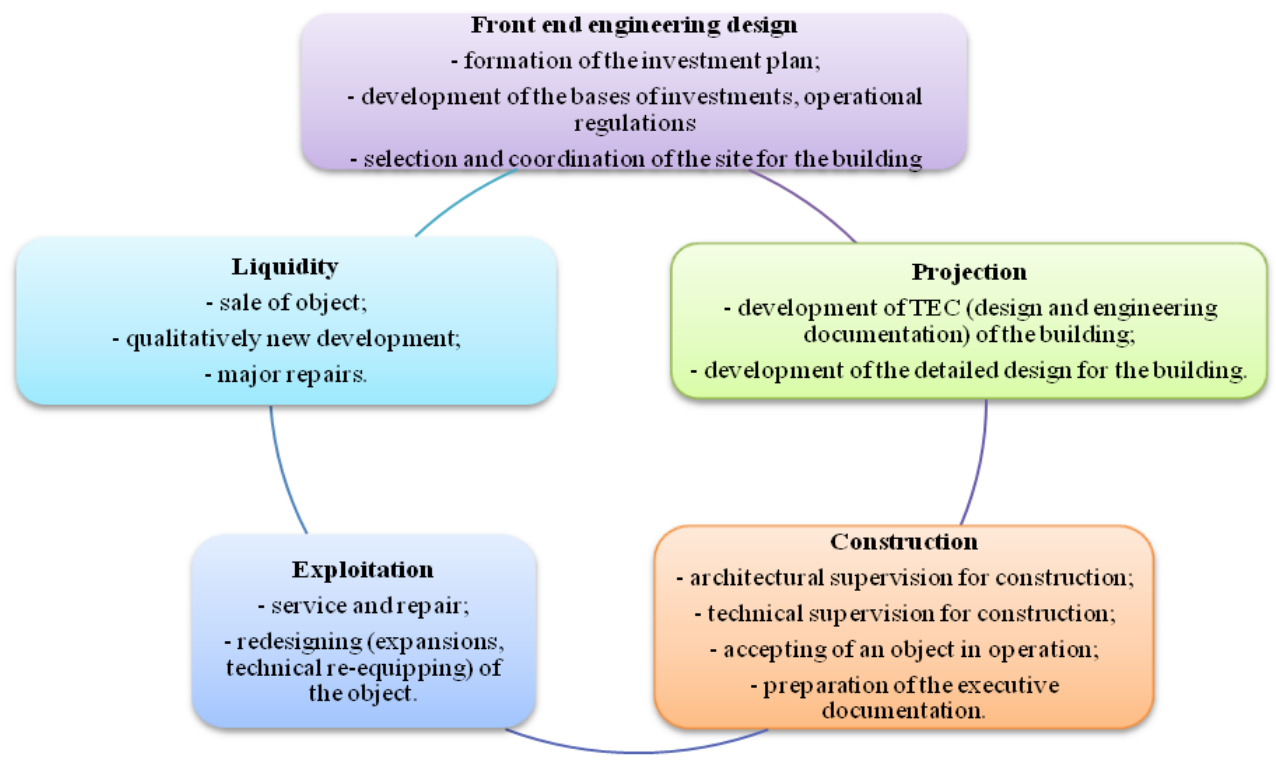

Fig. 1. Main stages of realization of the investment and construction project

Let's represent interconnection of the life cycle of the project and the risk level in the following graphical model (fig. 2). A1 project in this model is the investment building project with high risk degree at the pre-investment step and its following decline. A2 project is the investment building project, managers of which manage by the degree of risk 
on the pre-investment and investment steps. Regardless of management risk, both projects have a tendency to reduce the risk degree with approach to the operational step [6].

Consequently, stages and steps of the investment project life cycle are reviewed and interconnection with the risk degree is analyzed. On the basis of the data in Table 1 and Figure 2, it can be concluded that the correction for the risk in the determination of the discount rate is closely bounded to the project life cycle and as the different steps have different risk levels, it necessity for application of the variable discount rate on the different steps of the design period of the project should be considered.

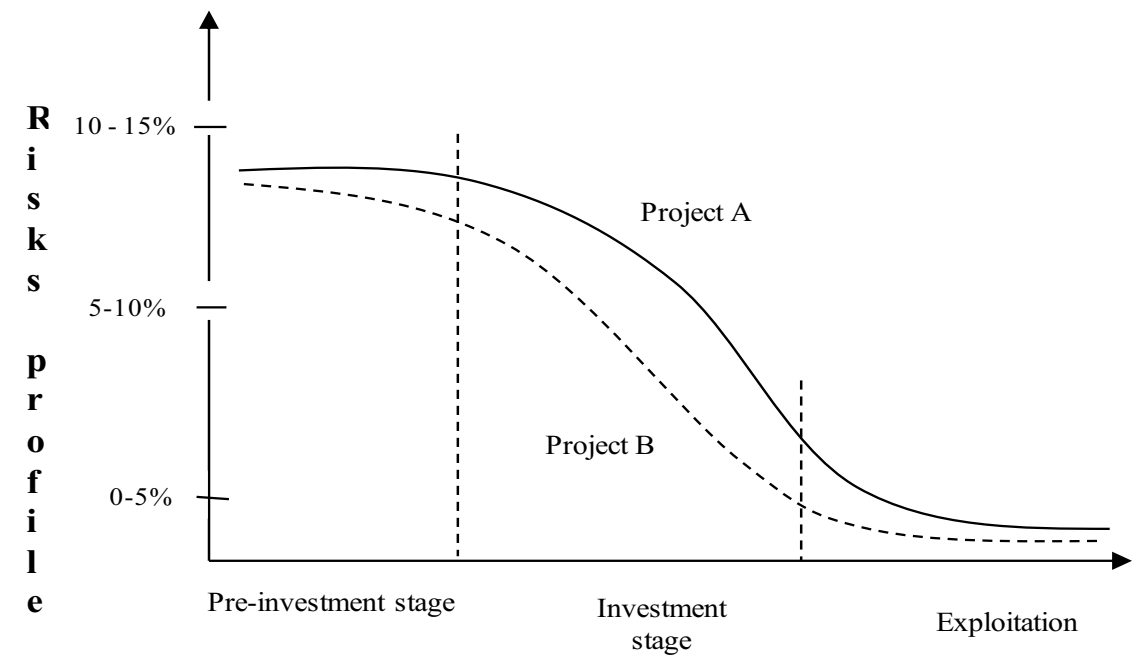

Stages of the construction industry institute life cycle

Fig. 2. Interconnection of the economic life of the project and the degree of risk

There was offered to consider the possibility of usage of the applying of variable discount rate at different steps of the design of the project period in the previous section. Its was proved that on the beginning of the calculated period of investment building project the degree of risk of the project failure is maximum and decreases with approach to the end of the life cycle of the project. There is a reducing trend of the discount rate during the time by the reducing of the risk of investment loss degree as they approach the production step, as well as improvement of the country's financial markets and their governance [7]. Besides, political risk of the long-term investment decreases with the improvement of the legislation and improvement of the foreign economic and trade relations contributes to the convergence of the discount rate of the Russian commercial structures with lower rates for developed countries.

\section{Results}

For these reasons performing calculations on effectiveness of the investment building project with consideration of the gradually decreasing discount rate is theoretically correct nowadays. So, the mathematical model for calculating the degree of risk at the different steps of the project life cycle, which posed as dependence function for some parameters $x, y$ and $t$ is proposed.

$$
R=f\left(x_{1} ; x_{2} ; x_{3} ; \ldots ; x_{n} ; t\right)+f\left(y_{1} ; y_{2} ; y_{3} ; \ldots ; y_{n} ; t\right)
$$


where, $x$ is the internal risk factors; $y$ is the external risk factors; $t$ is the lifecycle of the investment building project.

Then the calculation formula of the discount rates on the different steps of the economic life cycle of the project looks as follows:

$$
E=R+d,
$$

where, $\mathrm{d}$ is the risk-free rate of return; $\mathrm{R}$ is the risk rate of the investment building project.

Risk-free rate of return serves as a standard below which shouldn't be any discount rates in the calculation of the discount rate. It means the alternative variant of investments upon which investor gets incomes and doesn't risk to lose the invested capital. For this reason, investor always requires for profitability in no way below the risk-free rate of return when investing their funds in the investment project, which is always accompanied by a certain degree of risk. Russian state government stocks of the federal loan in our country can be considered as the risk-free rate of return. Rate of the state government stocks of the federal loan reserves is $10.5 \%$ nowadays. Sometimes evaluators use the refinancing rate, which currently assumes the value of $10 \%$.

Graphical model (fig. 3) of the calculation of the variable discounting rate represents as a graph, which determines values of the discounting on the different steps of the economic life cycle of the project $[8,9]$.

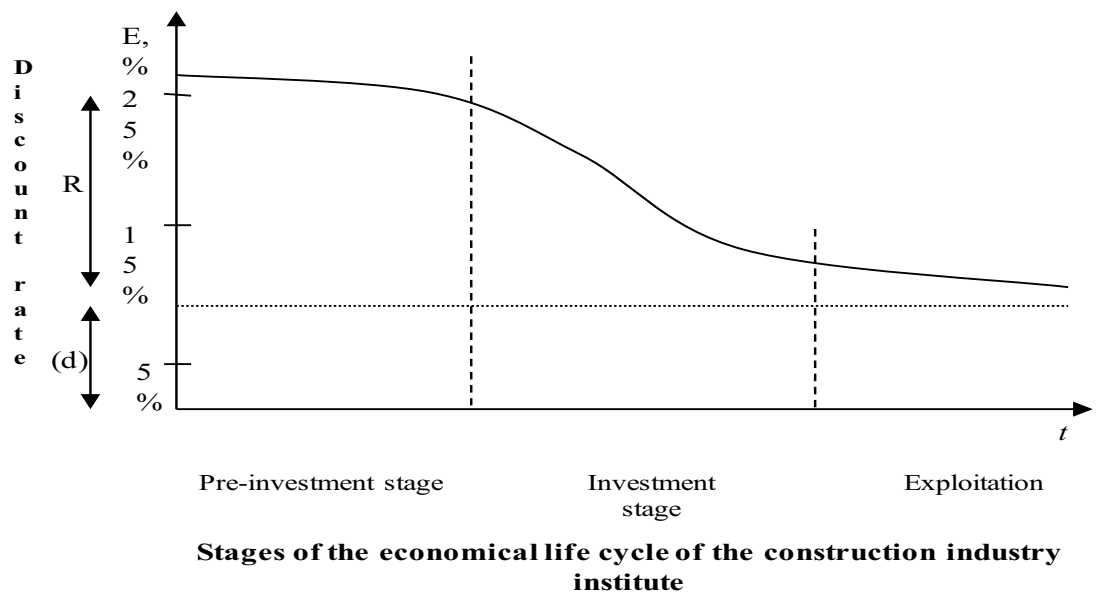

Fig 3. Model of calculation of a variable discount rate at the different stages of the project life cycle (ZhTsP)

\section{Discussions}

The presented model reflects discount rate of the investment building project through its risk degree on the different stages of economic project life cycle and considers risk-free rate of return as profitability of alternative investments, which is the standard value, below which discount rate shouldn't be accepted, otherwise it means the loss of possibility to generate income.

Offer of usage of the variable discount rate is caused by the increasing of the investment building project effectiveness, thanks to discount rate, which declines over time. Adoption of the similar rate deprives many projects of attractiveness for investors, because it decreases the results of the assessment of effectiveness. The regularity that is the higher discount rate, the worse the results of the investment building project effectiveness 
assessment is right. For evidence of impact of the discount rate on the assessment of the effectiveness and decision-making its offered to calculate the performance indicators of the real investment building project with application of fixed and variable discount rate and analyze the attained results.

\section{Conclusion}

On the basis of the model of calculation of the discounts rate on the different economic project it was concluded that discount rate must change its value depending on life cycle the identified risk classification of the investment building project. Offer to use variable discounting rate is caused by the increasing of the investment building project effectiveness, thanks to declining discount rate over time, while the adoption of the similar rate deprives many projects of attractiveness for investors, because it decreases the results of the assessment of effectiveness. For evidence of impact of the discount rate on the assessment of the effectiveness and decision-making its offered to calculate the performance indicators of the real investment building project with application of fixed and variable discount rate and analyze the attained results.

\section{References}

1. S.S. Uvarova, V.S. Kankhva, S.V. Belyaeva. Economic stability of construction enterprises and projects, MGSU (2011)

2. B. Herazo, G. Lizarralde. Sustainable Cities and Society, 26, 240-254 (2016)

3. E.M. Kiseleva, M.L. Nekrasova, M.A. Mayorova, M.N. Rudenko, V.S Kankhva, International Review of Management and Marketing. 6, 95 (2016)

4. R. Evangelista, A. Vezzan, A firm-level analysis, 39, 1253-1263 (2010)

5. H.M. Gumba, V.U. Mikhailov, V.V. Gamuletskiy. Formation of the mechanism of innovative-strategic development of construction enterprises, MGSU (2012)

6. R. Bucher, S.J. Couch. International Journal of Marine Energy, 2, 28-42 (2013)

7. I.G. Lukmanova, A.G. Korolyov, E.V. Nezhnikova, Project Management, MGSU (2013)

8. N.Y. Yaskova. Investment and Construction Processes Development in the Context of Globalization, IAICE (2009)

9. P.G. Grabovyi, I.P. Avilova, A.V. Sharapova, Life Science Journal, 11, 1097 (2014) 